\title{
Inhibition and adjective learning in bilingual and monolingual children
}

\author{
Hanako Yoshida ${ }^{1}$, Duc N. Tran ${ }^{1}$, Viridiana Benitez ${ }^{2}$ and Megumi Kuwabara ${ }^{2}$ \\ ' Department of Psychology, University of Houston, Houston, TX, USA \\ 2 Psychological and Brain Sciences, Indiana University, Bloomington, IN, USA
}

Edited by:

Frederic Dick, University of California San Diego, USA

Reviewed by:

Barbara T. Conboy, University of Washington, USA

Nadja Althaus, University of Oxford, UK

\section{*Correspondence:}

Hanako Yoshida, Department of Psychology, University of Houston, 126 Heyne Building, Houston, TX 77204-5022, USA.

e-mail:yoshida@uh.edu
The ability to control attention - by inhibiting pre-potent, yet no longer relevant information - is an essential skill in all of human learning, and increasing evidence suggests that this ability is enhanced in language learning environments in which the learner is managing and using more than one language. One question waiting to be addressed is whether such efficient attentional control plays a role in word learning. That is, children who must manage two languages also must manage to learn two languages and the advantages of more efficient attentional control may benefit aspects of language learning within each language. This study compared bilingual and monolingual children's performances in an artificial word-learning task and in a non-linguistic task that measures attention control. Three-year-old monolingual and bilingual children with similar vocabulary development participated in these tasks. The results replicate earlier work showing advanced attentional control among bilingual children and suggest that this better attentional control may also benefit better performance in novel adjective learning. The findings provide the first direct evidence of a relation between performances in an artificial word-learning task and in an attentional control task. We discuss this finding with respect to the general relevance of attentional control for lexical learning in all children and with respect to current views of bilingual children's word learning.

Keywords: attentional control, novel adjective learning, attentional network test

\section{INTRODUCTION}

The ability to control attention - and to inhibit conflicting irrelevant information - is an essential skill in all of human learning (e.g., Rescorla and Wagner, 1972; Mackintosh, 1975; Medin and Schaffer, 1978; Posner, 1980; Duncan, 1984; Chun and Jiang, 1998; Kruschke, 2003; Davenport and Potter, 2004; Blaga and Colombo, 2006; Richards, 2008) and therefore one that has been studied at multiple levels of analysis, including the behavioral (e.g., Rescorla and Wagner, 1972; Grossberg, 1982), cognitive and modeling (e.g., Kruschke, 2001; Kruschke et al., 2005; Brady and Chun, 2007), and neural levels (e.g., Desimone and Duncan, 1995; Preston and Gabrieli, 2008). Recently, there has been increasing evidence that growing up bilingual has measurable positive effects on the ability to control attention and to inhibit pre-potent but task-irrelevant information in non-verbal tasks. This advantage for bilinguals has been broadly shown in adults (Costa et al., 2008) and in young children in the process of becoming bilingual (Mezzacappa, 2004; Carlson and Meltzoff, 2008; Bialystok and Viswanathan, 2009; Kovács and Mehler, 2009; Bialystok, 2010). All this evidence indicates that learning two languages alters general attentional processes.

One question waiting to be addressed is whether such efficient attentional control is also related to early language learning itself. Children who must manage two languages also must manage to learn two languages. The main hypothesis motivating the present study is that efficient attentional control is relevant to lexical learning generally, for both monolingual and bilingual children.
In addition, we hypothesize that bilingual children, because of their history in learning two languages and more advanced attentional control may be better lexical learners in some tasks. As yet, there is no direct evidence for a role of attentional control in lexical learning per se, however, there is a large literature suggesting that individual differences in attention in infancy are strong predictors of individual differences in later lexical learning (TamisLeMonda and Bornstein, 1989; Dixon and Smith, 2000, 2008), a fact that implicates a role for the development of attentional processes in effective word learning. Other studies also point to the importance of competitive processes in lexical development, competitions which are resolved through the inhibition of weaker candidates by stronger ones (Snedeker and Trueswell, 2004; Mani and Plunkett, 2007; Fernald et al., 2008; Snedeker and Yuan, 2008; Vouloumanos and Werker, 2009; Mayor and Plunkett, 2010; Yu and Smith, 2010; Yoshida and Hanania, in press, see also Diamond et al., 1994; Lalonde and Werker, 1995; Conboy et al., 2008 for phonetic learning). The importance of competition in lexical access thus also suggests a possible role for attentional control. The goal of the present study is to provide evidence for relation between attentional control and lexical learning. The study compares bilingual and monolingual children's performances in an artificial wordlearning task expected to benefit from effective attentional control and in a non-linguistic assessment of attentional control.

The artificial word-learning task chosen as the lexical learning task is a task that asks children to map novel adjectives to the 
properties of objects. This task has been widely used to study early lexical learning across many different languages and the research shows that adjective learning (relative to noun learning) is generally difficult across languages (Nelson, 1973; Dromi, 1987; Jackson-Maldonado et al., 1993; Gasser and Smith, 1998). Further, this difficulty has been shown to be due, at least in part, to a pre-potent tendency for children to interpret novel words as nouns (Gentner, 1982; Markman, 1989; Waxman, 1990; Gasser and Smith, 1998; Mintz and Gleitman, 2002; Sandhofer and Smith, 2007). This prepotency could emerge because nouns are conceptually prior (Gentner, 1982) or in part because children, across many different languages, learn many nouns before they learn adjectives and thus build the expectation that an unknown word is likely to label an object rather than a property of an object (see Gasser and Smith, 1998, for a review). Consistent with this idea, Sandhofer and Smith (2007) showed that it was easier to teach color words to very young children who knew few nouns than it was to teach color words to children who knew many nouns. They hypothesized that learning nouns interfered with mapping words to properties rather than objects. Further, many studies have shown that young children often interpret a novel adjective (e.g., "This is a blickish one") as a noun that refers to the object rather to a property of that object (Au and Markman, 1987; Landau et al., 1988; Au and Laframboise, 1990; Smith et al., 1992; Clark, 1997; Mintz, 2005). All this suggests that nouns (or object names) function for young children as the default interpretation for a novel label. Thus, this bias may need to be inhibited in order for children to map a novel adjective to a property of an object rather than to the object itself.

The particular variant of the adjective-mapping task used here derives from previous studies (e.g., Waxman, 1990; Waxman and Klibanoff, 2000; Mintz and Gleitman, 2002; Mintz, 2005). A sample trial is shown in Figure 2. Childrenare presented with known objects (e.g., a duck) with novel properties and a novel adjective ("This is a blickish duck") and then asked to indicate which other objects (e.g., other ducks) - some with the same property and some without - are also blickish. Even in this task with known objects with known names, and the critical property being the only difference between the choices, the task is difficult for young children. When all the objects are in members of the same object category, children's choices are often random, consistent with the idea that they take the novel word to refer to the category and thus that all choices are equally good. Children's difficulty in this task is remarkable given that the task provides clear linguistic information that the novel word is an adjective (Mintz and Gleitman, 2002). Despite the difficulty of the task, children's performance in it has been shown to be sensitive to task factors that might be expected to push children away from an interpretation of the novel word as a noun (Waxman, 1990; Waxman and Klibanoff, 2000; Mintz and Gleitman, 2002; Mintz, 2005). Children's general difficulty in this task and the bias to interpret the novel word as a noun appears to persist over a protracted developmental period, even after children's vocabularies shift include a variety of kinds of different words that are not nouns. Indeed, a number of studies have shown that when the artificial word is not a noun, but an adjective or even a verb, there is a robust tendency to treat the novel word as if it were the name of an object by children as young as 2 years and as old as 4 years of age (Gentner, 1982; Markman,
1989; Waxman, 1990; Gasser and Smith, 1998; Kersten and Smith, 2002; Mintz and Gleitman, 2002; Imai et al., 2005; Kersten et al., 2006; Sandhofer and Smith, 2007; Yoshida, in press).

In sum, the adjective-mapping task as used by Mintz and Gleitman (2002); Waxman (1990), and Waxman and Klibanoff (2000) provides a lexical context in which one might expect attentional control - and the ability to shift attention away from the object to a property of the object - to play a role. If this construal is correct, then performance in this task should be related, within individuals, to performance in a task directly that measures attentional control. Moreover, if this construal is correct, one might expect bilingual children to be better able to resist the hypothesized pre-potent tendency to map novel words to an object category. As far as we know, the present study is the first to examine bilingual children's interpretation of a novel adjective in an artificial word-learning task (see Kaushanskaya and Martin, 2009 for adults' novel word learning), although a variety of researchers (Au and Glusman, 1990; Merriman and Kutlesic, 1993; Davidson et al., 1997; Davidson and Tell, 2005; Byers-Heinlein and Werker, 2009; Houston-Price et al., 2010) have examined other forms of artificial word learning in bilingual children and have found some potentially relevant differences that we will discuss in the General Discussion.

The measure of attentional control that we chose is the attention network test (ANT), developed by Fan et al. (2002). The children's version used in the present study was developed by Rueda et al. (2004). This test measures children's ability to shift attention way from pre-potent information to task-relevant information and has been shown to be sensitive to the developmental differences in inhibition and attentional control between bilingual and monolingual children (Yang, 2004; Yang et al., 2005; Carlson and Meltzoff, 2008 , for bilinguals' attentional advantage in other attention tasks, see Bialystok and Martin, 2004; Bialystok and Shapero, 2005). The variant of the ANT we used in the present study is one suitable for children as young as 4 years old (4-year-olds: Yang, 2004; 5 to 6-year-olds: Carlson and Meltzoff, 2008). Here we extend the task to even younger children, 3-year-olds whose performances in the ANT have never been documented. The task is illustrated in Figure 1: participants were asked to point to the mouth of a target fish facing a certain direction among other fish on a computer screen. The direction of the target fish faces does not change throughout the task, but the facing direction of the distractor fish does, sometimes presenting direction information congruent to that of the target fish and sometimes presenting incongruent information. Thus the task requires the child to inhibit attention to this sometimes-misleading information, with the principle measure of performance in the task being accuracy and overall response time (RT), and RTs for congruent versus incongruent trials. Advantages in this task have been reported for bilingual children over monolingual children (Yang, 2004; Yang et al., 2005; Carlson and Meltzoff, 2008). We expect to find this result as well.

The new question is whether the degree of attentional control as measured in this task - for both bilingual and monolingual children - predicts their success in the novel adjective-mapping task. If successful adjective-mapping involves shifting away from the prepotent tendency to map labels to nouns, then performance in the adjective learning task might involve some of the same attentional control measures assessed by the ANT, and thus performance in the 
Congruent

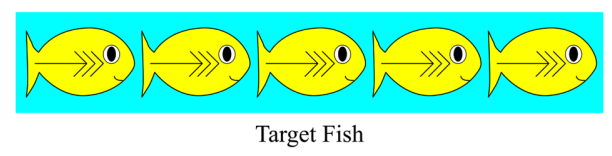

Incongruent

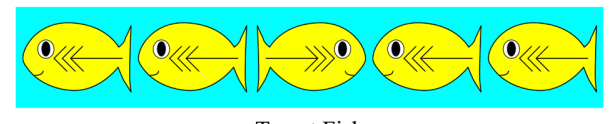

Target Fish

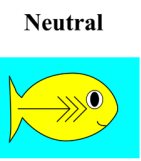

FIGURE 1 |A set of stimuli used in the Attention Network Test for three types of trials.

\section{A}
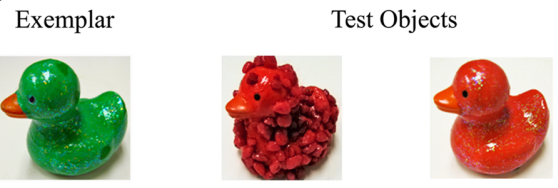

B Exemplar
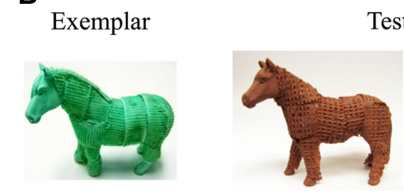

Test Objects

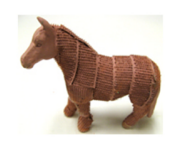

FIGURE 2 | Sets of stimulus objects used in the adjective tasks. (A) Control task. (B) Main task.

two tasks may be related in individual children. If bilingual children are advanced relative to monolingual children in attentional control, they might perform better than monolingual children in both the ANT and the adjective-mapping task. Such a result would provide the first developmental evidence of a link in individual children between how they map new words and attentional control.

There are a number of methodological challenges in any study comparing monolingual and bilingual children (e.g., Bialystok, 2001; Goetz, 2003; Carlson and Meltzoff, 2008; see Grosjean, 1998, for a review), including matching participants in culture, in language ability, and in ensuring the fairness of the linguistic material and tasks for the two different groups. Accordingly, we note the issues and the rationale for the present comparisons here. All the children in the present study live in the United States. The monolingual children spoke English and the bilingual children had early exposure to a variety of different languages in addition to English. All of the bilingual children spoke a language other than English in their home. We measured vocabulary in both English and the home languages as bilingual children typically have different levels of experience with each language (Pearson et al., 1997). English vocabulary size was matched (less than $10 \%$ difference) for the two groups. Most bilingual children were tested in the novel adjective task in English in an effort to equate the linguistic task for the two groups of children. This potentially puts the bilingual children at a disadvantage but we are predicting, on the basis of expected better attentional control, an advantage for them in the task. Some bilingual children were tested in the home language. We did this to be fair to those very young ( 3 years old) bilinguals who had larger non-English than English vocabularies.

To ensure that children in both groups understood the adjective task, we also tested all children in a control task, structured like the novel adjective-mapping task except that the adjectives used were ones commonly known to young children. Finally, because languages differ in the prepotency of nouns versus other relational terms, the bilingual children could differ from the monolingual children in the adjective-mapping task not because of greater attention control, but because they know fewer competing nouns or more relational meanings. Although we will report measures that attempt to directly address these issues, note that these issues work against the main experimental hypothesis: that there is a relationship in individual children between performance in the non-linguistic ANT and performance in the novel adjective task. In particular, the experiment tests the hypothesis that children with greater attentional control as tested in a non-language task will be better able to inhibit the pre-potent mapping of novel words to nouns in an adjective-mapping task. The expectation is that bilingual children in general will show both greater executive control in a non-linguistic task and will exploit this greater attentional control to better map novel adjectives to novel properties in the adjective task. This hypothesis speaks to the larger idea that attentional control and inhibitory processes that emerge through bilingual language learning experiences also play a role in lexical learning. Such a result would indicate the involvement attentional control in word learning, and also raise the possibility of a bidirectional relation between language learning and attention: learning two languages may create greater facility in attentional control which in turn may influence the speed and processes by which new words are learned.

\section{MATERIALS AND METHODS PARTICIPANTS}

Forty 3-year-old children participated. Twenty participants were monolingual English learners with a mean age of 36.66 months (range: 29.47-43.16) and 20 were bilingual learners (e.g., English-Chinese, English-French, English-Spanish, EnglishRussian, English-Urdu, English-Vietnamese) with a mean age of 38.86 months (range: 30-45.53). There were one English-Chinese, one English-French, 11 English-Spanish, one English-Russian, four English-Urdu, and two English-Vietnamese bilingual learners. Participants were recruited from local preschools in Houston, Texas. Mothers of both monolingual and bilingual children were asked to complete a language exposure questionnaire that specified the language(s) their child uses and the language(s) used by family and caregivers who interact regularly with the child. This information was used to estimate the number of hours per day 
that the child hears the non-English language. The questionnaire indicated that all the bilingual children included in the study were mostly early sequential bilinguals who had early exposure to a nonEnglish language (mean age for their first exposure $=0.35$ months, $\mathrm{SD}=1.348$ ) and used the non-English language at home but used English outside of the home. The mean number of hours of exposure per day of bilingual children to English and to the home language was $7.45(\mathrm{SD}=3.47)$ and $6.73(\mathrm{SD}=2.69)$, respectively.

An effort was made to match bilingual and monolingual children in socioeconomic status (SES). Parents were asked to fill out the SES queries taken from the MacArthur Network on SES and Health (Fenson et al., 1993). The key sections used for the current study consider (a) how respondents self-rank their status in the community (on a scale of 1-10), (b) how they self-rank themselves in the nation (scale of 1-10), (c) their highest educational level (scale 1-20), and (d) family income (scale 1-20). Table 1 shows the mean scores provided by parents of monolingual and bilingual participants for these four measures. We found no significant group difference in these measures in the set of our participants.

\section{LANGUAGE MEASURES}

To assess the children's vocabulary, we asked the mothers of the children to complete the MacArthur-Bates Communicative Development Inventories (MCDI; Fenson et al., 1993), a parent checklist of productive vocabulary. There were eight sections of the MCDI checklist used in the study, classified into three lexical categories; noun, verb, and adjective. The nouns were words contained on six sections of the CDI - Animals, Vehicle, Toys, Food and Drink, Small Household Items, and Furniture and Rooms. Verbs were the Action Words on the CDI, and Adjectives refer to the category of Descriptive Words on the CDI. For English monolingual children, the American English version was used. For bilingual learners, the same English measure was used along with a parent checklist for the home language. For Spanish bilinguals, we used the Spanish version of the MCDI (Jackson-Maldonado et al., 2003), and for
Chinese- and Vietnamese-speaking bilingual children, we developed language-specific versions of the MCDI by translating the American English and Japanese versions (Ogura and Watamaki, 1997; see also Ogura et al., 1993). For all other languages, we used translations of the English MCDI. All translations were done by adult native speakers of the language who were also fluent in English. By these measures, four bilingual children had a larger total vocabulary score in English (greater than 10\% difference), and nine other bilingual children had comparably sized vocabularies in their two languages (less than 10\% difference). These 13 bilingual children were all tested in the adjective task and the ANT task in English. There were seven bilingual children for whom the size of their non-English vocabulary was greater than that of their English vocabulary (more than 10\% difference). The home languages of these children were Spanish $(n=6)$ and Vietnamese $(n=1)$. These seven bilingual children were tested in both the adjective task and the ANT in their home language by a native speaker of that language.

Table 2 provides the mean total English vocabulary size and the mean number of nouns, adjectives, and verbs known by the monolingual children. For the bilingual children, we provide measures of the English vocabulary, the home language vocabulary, and also report the mean vocabulary size for the dominant and non-dominant languages, as well as the several ways of measuring vocabulary size across the two languages. We provide all these measures because of the complexity of the issue of just what counts as the vocabulary size for bilingual children with respect to comparisons with monolingual children (e.g., Pearson et al., 1993; Marchman et al., 2004; Patterson and Pearson, 2004). More specifically, the seven vocabulary measures that were used for bilinguals were (1) the so-called dominant language vocabulary size (the size of the largest single vocabulary), (2) non-dominant language vocabulary size (the size of the smallest single vocabulary), (3) English vocabulary size, (4) non-English home language vocabulary size, (5) the combined vocabulary size (the sum of the

Table 1 | Mean scores for the key socioeconomic status (SES) measures used from the MacArthur Network on SES and health.

\begin{tabular}{llll}
\hline Group & Rank in community & Rank in the nation & Highest education \\
\hline Monolingual & 5.86 (SD 1.32) & 6.17 (SD 1.53) & 16.63 (SD 2.75) \\
Bilingual & 7.05 (SD 1.89) & 7.14 (SD 1.47) & 15.00 (SD 2.56)
\end{tabular}

Table 2 | Mean productive vocabulary of languages based on the MacArthur-Bates Communicative Development Inventories.

\begin{tabular}{lcccc}
\hline Group/Age (months) & Number of nouns & Number of verbs & Number of adjectives & Total number of words \\
\hline Monolingual/(36.7 months) & & & \\
English & $177.9[0.59]$ & $81.6[0.26]$ & $48.5[0.25]$ & 308.0 \\
Bilingual/(38.9 months) & & & & \\
Dominant language & $177.3[0.58]$ & $83.2[0.27]$ & $48.4[0.15]$ & 308.9 \\
Non-Dominant & $84.4[0.69]$ & $30.5[0.14]$ & $15.5[0.18]$ & 130.4 \\
English & $131.2[0.66]$ & $56.1[0.20]$ & $33.1[0.17]$ & 220.4 \\
Non-English native & $150.7[0.58]$ & $69.2[0.23]$ & $36.9[0.18]$ & 256.8 \\
Combined & $238.9[0.60]$ & $105.5[0.26]$ & $59.5[0.15]$ & 403.9 \\
Conceptual vocabulary & $191.1[0.59]$ & $88.6[0.27]$ & $45.4[0.14]$ & 325.1 \\
Translation equivalents & $69.6[0.72]$ & $18.0[0.19]$ & $8.7[0.09]$ & 96.4
\end{tabular}


words known in the two languages), (6) total conceptual vocabulary size (a combination of vocabulary scores in both languages considering only words describing the same concept as one word), and (7)translation equivalent vocabulary which is the number of overlapping words (words indicated by parents as known in both language lists). The brackets contain the proportions of these vocabulary scores that are nouns, adjectives, and verbs.

\section{ADJECTIVE TASK}

All children participated in two adjective tasks. One task, the control task, measured children's ability to pick the labeled object (from a set of two test objects) when it was labeled with a known adjective (e.g., bumpy). The four known adjective labels in English were selected from a prior pilot study with young English-speaking children and were bumpy, spotted, shiny, and holey (see the Appendix for the terms used for the children not tested in English). This task provides a measure of the comparability of structure of the task - and the carrier phrases - for monolingual and bilingual children. If children understand the task and the phrasing, they should all do well since the adjectives themselves should be already known.

To create the stimuli, the appropriate properties were realized on the target objects by covering the surface of the objects with small raised bumps, small colored spots, shiny sparkle paint, and cutting small round holes through the toy objects, respectively. The toy objects were approximately $10 \mathrm{~cm}^{3}$ and consisted of typical representations of object categories: duck, snake, horse, straw, truck, spoon, frog, and scissors. The purpose of the control task is two-folds: (1) to ensure that bilingual and monolingual children tested in English and bilingual children tested in a language other than English all understood the task equally well, (2) to measure their linguistic performances a condition which requires no competition resolution. For these control trials, the child was shown an exemplar object that was a member of a known category (e.g., duck), of a specific color (e.g., green) with the to-be-tested property (e.g., shiny) and was told, "This is a shiny duck." This labeled exemplar was removed. The child was then shown two new ducks. Both ducks were a new color (e.g., both were red) and one duck was shiny but the other was not (e.g., it was rough instead). The two choice ducks were pointed to and the child was then asked, "Can you get me the duck that is shiny?" There were eight control trials with each property tested twice (once each with a particular set of different objects, e.g., a duck and a truck) for testing four adjectives. The eight trials were randomly ordered for each participant. Figure 2A shows one of the eight stimulus sets used in the control task.

The structure of the main experimental task, the novel adjective task, was identical to that of the control task except that the textural properties were highly novel with no names lexicalized in any of the languages known by the children and the labels used were novel made-up adjectives. There were eight experimental trials with each property tested twice (once each with a particular set of different objects, e.g., a duck and a truck) for testing four novel adjectives. The eight trials were randomly ordered for each participant. Figure 2B shows one of the eight stimulus sets used in the main task. The four target novel properties used were stringwrapped, pipe-cleaner-attached, a surface made out of soft sponge pieces, and a Velcro surface. These properties were labeled with the novel names blickish, dakish, talish, and wuggish, respectively. The list of labels used for children tested in the home language is provided in the Appendix.

\section{ATTENTION NETWORK TEST}

The task was a child version of the ANT, conducted on a portable Dell 15-inch touch-screen laptop using E-Prime software. The children sat at a comfortable distance from the screen and used their index finger to touch the target displayed on the screen. The procedure began with 10 practice trials in which participants were instructed to feed a hungry fish by touching its mouth with their index finger as quickly as possible. A fixation point was presented throughout the task in the center of the screen. The target (i.e., the hungry fish) was either a single fish (neutral condition) or the middle fish in a row of five fish. The single fish could appear above or below the fixation point. The row of five fish could face left or right, and the stimuli could be in a congruent or incongruent direction. The congruent trial had all five fish facing the same direction $(\rightarrow \rightarrow \rightarrow \rightarrow \rightarrow$ or $\leftarrow \leftarrow \leftarrow \leftarrow \leftarrow$; see Figure 1), and the incongruent trial displayed the middle fish facing the opposite direction from the others $(\rightarrow \rightarrow \leftarrow \rightarrow \rightarrow$ or $\leftarrow \leftarrow \rightarrow \leftarrow \leftarrow$; see Figure 1$)$. Children were told that sometimes the fish would appear alone, and other times it would swim together with other fish. In all cases, they were instructed to concentrate on the one fish in the middlethe hungry fish. They were also asked to keep their eyes on the fixation point during the task. Trained experimenters administered the trials and gave feedback to ensure that children comprehended the task, and all children in both groups managed to get it right within no more than 10 trials. Once they were familiarized with the task, testing trials were administered.

There were 48 testing trials presented in two blocks (i.e., 24 trials in each block) with a 60-s break between the blocks. The procedure was identical to the practice trials, except that the experimenter no longer provided feedback. Instead, participants were presented with automated trials and received automated sound feedback (from the laptop): "Woo hoo!" for correct responses and "Huh!" for incorrect responses. The completion time was approximately $15 \mathrm{~min}$. The dependent measures were accuracy (percent correct) and RT.

The three tasks - the control adjective task, the novel adjective task, and the ANT - were presented to children in one of two orders such that the two adjective tasks were always separated by the ANT. Thus the two orders were control adjective-ANT-novel adjective or novel adjective-ANT-control adjective.

\section{RESULTS}

We consider the performances of the two groups of children first in the adjective task, and then in the ANT. We then consider the data most relevant to the experimental question, the relationship between children's performances in the two tasks. Finally we consider how performances in both tasks relate to the child's vocabulary size.

\section{ADJECTIVE TASK PERFORMANCE}

As shown in Figure 3, all children performed well in the Control task and there were no differences between the two participant groups, $t(38)=1.00, p>0.4$. Performance was well above 
chance for both groups, $t(19)=2.75, p<0.05$ (monolingual), and $t(19)=3.18, p<0.05$ (bilingual), indicating that children in both language groups understood the task. In contrast, as also shown in Figure 3, performance by the bilingual children was superior in the main novel adjective task, $t(38)=-4.72, p<0.001$, and only the bilingual children selected the property matching the object at a rate above chance, $t(19)=9.57, p<0.001$; the monolingual children performed at chance. For monolingual children only, performance in the main task was reliably less than in the control task, $t(39)=9.1, p<0.001$; bilingual children performed as well in the novel word-mapping task as in the known adjective control task. These results show for the first time an advantage for bilingual children over monolingual children in mapping a novel adjective to a novel property.

As for the effect of language used in the task among bilingual children, there were no reliable differences in performance between the bilingual children $(n=13)$ tested in English and those tested in the home language $(n=7)$ in the main task, $t(1$, $18)=-0.017, p=0.987$ nor in the control task $t(1,18)=-0.043$, $p=0.470$. The finding that bilingual children, in general, are better able than monolingual children to map the novel adjective to the property is consistent with the main hypothesis that mapping adjectives requires inhibitory processes such as those that have been shown to be more advanced in bilingual children in nonlinguistic attentional tasks. Admittedly, there are alternative (and inter-related) reasons why bilingual children may do better in the novel adjective task other than attentional control per se, including that they may know more total words across both their languages and that they have learned multiple words with slightly different meanings for different objects. If these alternative accounts were correct and unrelated to the hypothesized advantage in attentional control, then one would not expect a stronger relation between language and performance in the adjective task than between performance in the ANT and the adjective task. The relevant results are presented after considering group performances in the ANT.

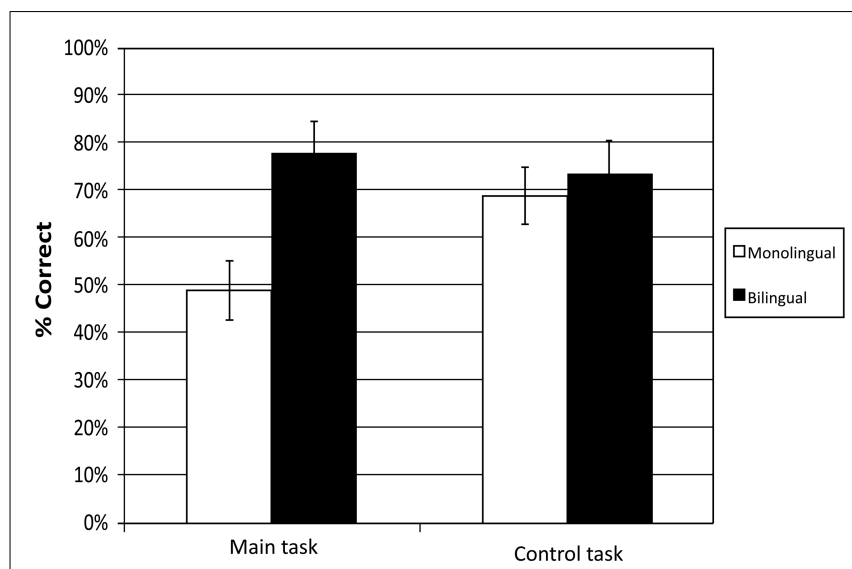

FIGURE 3 | Monolingual and bilingual children's percent correct on the main task, mapping novel labels to novel properties (left), and on the control task, mapping familiar labels to familiar properties (right) in adjective-mapping tasks.

\section{ANT PERFORMANCE}

Figure 4 shows the performances of the two groups of children, as measured by accuracy and RTs, in the ANT. Independent $t$ tests show that the bilingual children as a group were more accurate, $t(38)=3.26, p<0.01$, and also faster, although the difference in RTs did not reach statistical significance, $t(38)=1.12, p=0.25$. As expected, and as shown previously by Yang (2004), Yang et al. (2005), young bilingual children outperformed monolingual children in a non-linguistic task requiring attentional control.

\section{CORRELATIONS BETWEEN THE TWO TASKS}

The present adjective tasks used a force-choice task used by previous studies (Waxman, 1990; Waxman and Klibanoff, 2000; Mintz and Gleitman, 2002) in which the correct choice shares the target property and is a member of the same category and the alternative choice is also a member of the same category. This task structure make both test objects equally good under a noun interpretation. Given this structure, choosing the target item should be easy, especially if children merely thought that they should choose the most similar item to the exemplar object regardless of the instruction (that is, even without children map the adjective to the property). However, the results suggest that monolingual children did not successfully choose the target items in the novel adjective condition, and their success was only documented in the known adjective control condition, which differs from the experimental condition only in whether the adjective is known or novel. Monolingual children's success in this known adjective control condition
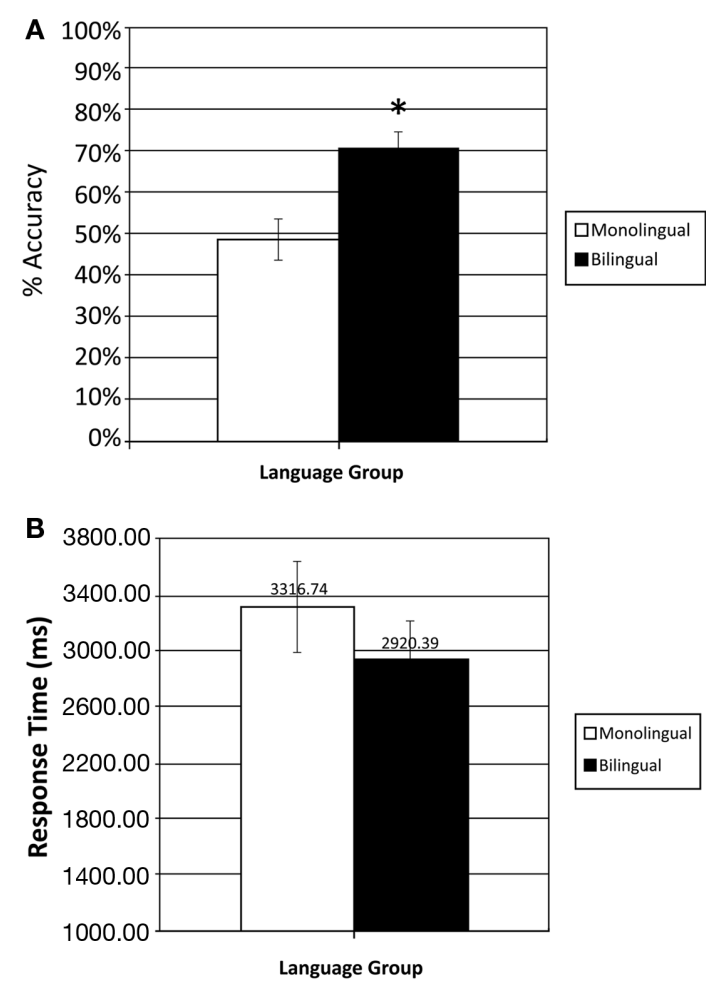

FIGURE 4 | Monolingual and bilingual children's percentage of correct responses $(A)$ and response time $(B)$ in the Attention Network Test. 
suggests that having knowledge of the adjective is crucial for them to inhibit attention to the noun category and select the object with the target a property. Bilingual children, in contrast, succeed both when the adjective is novel and when it is known. These results appear to be consistent with the prediction that bilingual children are better at inhibiting the pre-potent tendency to map words to noun categories. Alternatively it could be the case that bilingual children are better at inhibiting the pre-potent tendency to attend to the category and thus find the matching property (and would do so in a non-word-learning task). This account would also predict that they would be better able at learning adjectives - or any new word-meaning - that require them to inhibit strong biases and to adjust attention to the specifics of the present task. If these inhibitory processes are related to those in attentional control tasks, then individual children's performances in the novel adjective task and in the ANT should be related.

Consistent with this hypothesis, correlations calculated across all children (monolingual and bilingual) between performance in the novel adjective task and performance in the ANT, both in accuracy, $r=0.48, p<0.05$, and in RT, $r=-0.50, p<0.05$ were reliable. Figure 5A shows the scatterplot for accuracy and it indicates for the first time, that there is a relation between children's performance in a novel word-learning task and their performance

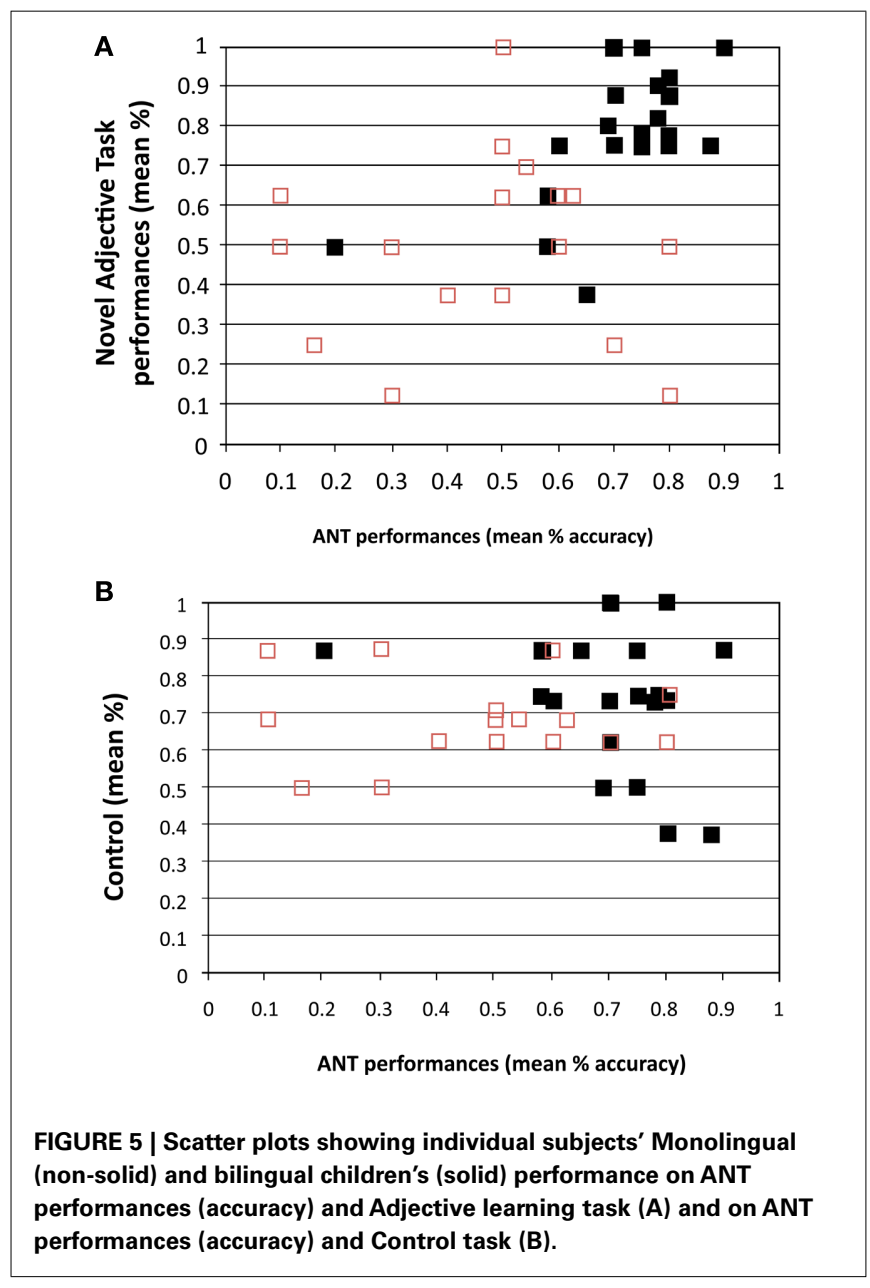

in a non-linguistic attentional control task. This observed relation appears specific to mapping a novel adjective to a novel property in that, as shown in Figure 5B, there is no relation between performance in the control task and the ANT by either accuracy or by RT.

Figure 5A, the scatterplot of performances in the main adjective task and in the ANT, shows that monolingual children generally performed poorly in both tasks. The few monolingual children who performed well in one task did not necessarily perform well in the other. Thus, the correlation between performance in the novel adjective-mapping task and in the ANT is much stronger for the bilingual children than for the monolingual children in accuracy (bilinguals: $r=0.637, p<0.01$; monolinguals: $r=0.038$, $p=0.875$ ) and RT (bilinguals: $r=-0.47, p<0.05$; monolinguals: $r=-0.279, p=0.23)$. How seriously one should take the possibility that performance in the word-mapping and attentional control task is related only for bilinguals is not clear since many monolingual children are performing very poorly in both tasks. Indeed, if we define passing in each task as performing above $75 \%$ correct, then most of the monolingual children $(n=14)$ failed both tasks, whereas more than half of the bilingual children $(n=11)$ passed both tasks. It is not, however, the case that bilinguals are generally better at all the tasks nor that the performances in all tasks correlate with executive control. The results from the known adjective control condition suggest no relation to the attentional control test performances.

It will be important in future work to trace the development of performance in novel word-mapping tasks and in attentional control tasks to document whether a relationship between wordlearning and inhibitory processes of attentional control emerges in monolingual children but just more slowly than in bilingual children.

\section{RELATION TO LANGUAGE}

One reason that bilingual children may have greater attentional control and perform better in the novel adjective task is because they know more total words. That is, something about language development generally (total known words) rather than having to manage two languages might promote development in both domains. To address this issue, we conducted a series of regression analyses asking whether vocabulary size predicted performance in the ANT and whether vocabulary size and ANT predicted performance in the novel adjective task. The measures of vocabulary size considered were English vocabulary size for the monolingual children, and combined vocabulary (English plus home language) size for the bilingual children. The multiple regression analyses indicate that individuals' vocabulary sizes do not predict ANT performances ( $p=0.716$ English, $p=0.315$ total, for bilingual children). For monolinguals, vocabulary size was negatively related to performance in the novel adjective task $t(3,29)=-2.41, p<0.05$; this result is consistent with Sandhofer and Smith's (2007) finding that children's ability to learn adjectives in an artificial language learning task at first declines with increases in vocabulary as nouns and object names initially dominate new acquisitions. Across both groups of children, the regression analyses indicate that performance in the novel adjective task was only reliably predicted by ANT scores, $t(3,29)=2.99, p<0.01$. We also considered three 
other measures, which are often used in the bilingual literature as measures of vocabulary size (measures of Dominant language size, English, and total conceptual vocabulary). The regression results using each these measures of bilingual vocabulary size were the same as the previous analyses. For the bilingual children individuals' vocabulary size does not predict ANT performances for any measure of bilingual vocabulary $(p=0.857, p=0.551$, and $p=0.61$, respectively). The regression analyses indicate that performance in novel adjective task was only reliably predicted by ANT scores, $t(4,18)=3.39, p<0.01$.

\section{DIFFERENT TYPES OF WORDS}

Previous work on bilingual toddlers suggests that the ability to learn different types of words and the relation of this ability to the lexical composition may be different for the two languages known by a bilingual child (Pearson and Fernández, 1994; Marchman et al., 2004; Conboy and Thal, 2006). To pursue the possibility that the composition of bilingual children's vocabulary may be related to performance in the adjective task and to ANT performance (and be perhaps a third variable that indirectly connects these two tasks), we considered whether different word types might be uniquely related to bilingual task performances. We have just shown that a variety of global measures of vocabulary (other than that of being bilingual) do not directly predict task performances but the relative numbers of nouns, adjectives, and other nonnouns might be reasonably expected to matter to performance in the novel adjective task. Table 2 shows the mean number of nouns, verbs, and adjectives for the monolingual children in English and for the bilingual children by the various measures of vocabulary size. A 2 (group) by 3 (word type) analysis of variance on English vocabulary reveals a main effect of word type $[F(1.38)=44.80, p<0.001]$ but no group effect $[F(1.38)=2.56$, $p=0.12]$ nor interaction $[F(2.38)=3.03, p=0.09]$. The composition of monolingual English-speaking children's vocabularies appear comparable to those of the bilingual children in that all children knew more nouns than they did verbs and knew more nouns than they did adjectives. A 2 (group) by (word type) analysis of variance was also used to compare the monolingual children's English vocabulary and the Bilingual lingual children's combined vocabulary. This analysis also revealed a main effect of word type $[F(1.38)=77.55, p<0.001]$ but no group effect $[F(1.38)=0.20$, $p=0.65]$ nor interaction $[F(2.38)=1.25, p=0.27]$. Thus, it seems unlikely that vocabulary compositional components can explain the present findings.

Next, we asked whether different lexical categories predict performance in the ANT and whether the different lexical categories and ANT predict performance in the artificial word task and we did this using all of seven possible measures of bilingual vocabulary. There was only one reliable relation between any measure of vocabulary and performance in the adjective task, and none between any measure of vocabulary and performance in the ANT task. The one reliable correlation is between the noun proportion scores from the dominant language measure which was negatively related to performance in the novel adjective task $t(4,19)=-2.16$; $p<0.05$, which again fits the idea that knowing many nouns makes learning adjectives harder and thus may contribute to the prepotent tendency of interpreting a novel word as an object name
(Sandhofer and Smith, 2007). Altogether, these analyses suggest that the relation between ANT performance and performance in the novel adjective task is not due to unique compositional components of early bilingual vocabularies. Instead, the results as a whole suggest that knowing many nouns makes mapping a novel adjective to a property more difficult but that individuals with greater attentional control as measured in a non-linguistic task are better able to make this mapping. In this way, the results show that some forms of word learning depend on shifting attention from pre-potent categories and thus may be supported by general cognitive skills of executive control. The results also show that this ability is more advanced in both a linguistic and non-linguistic task in bilingual children.

\section{GENERAL DISCUSSION}

The results make two main contributions. First, they show that children's performances in the novel adjective tasks are related to their ability to control attention in a non-linguistic task and are indeed more strongly related to attentional control than to vocabulary size. Second, the results show that young bilingual children are better able than monolingual children to map a novel adjective to a property, a task known to be difficult for young children across languages and believed to related to the prepotency for young children of interpreting novel words as nouns rather than as other kinds of meanings (see Gasser and Smith, 1998, for a review). The findings have implications for our understanding of why adjective learning is difficult, for the cognitive skills that children need to recruit to succeed in word-learning tasks, for mechanisms underlying word learning in general and for how those mechanisms might relate to the language learning history of individual children. They also provide new insights into the origins and nature of the developmental differences in attentional control and language learning in monolingual and bilingual children. We consider first the implications with respect to lexical learning in general and then with respect to bilingual language development.

\section{INHIBITORY PROCESSES AND WORD LEARNING}

The task used in the present experiment is one that measures children's first interpretation of a novel word, not their learning via multiple encounters with multiple examples. This kind of fastmapping task has been widely used in the study of early word learning as a way to understand the speed with which early vocabularies expand (Carey, 1978; Carey and Bartlett, 1978; Landau et al., 1988; Behrend et al., 2001; Mintz and Gleitman, 2002). A learner who can use the linguistic cues and the context to map a novel word to the correct component of information during a single encounter seems likely to more rapidly learn new words from hearing them used in context. This approach has been used to study children's learning of nouns (Carey, 1978; Carey and Bartlett, 1978; Landau et al., 1988), of adjectives (Waxman, 1990; Waxman and Klibanoff, 2000; Mintz and Gleitman, 2002), and verbs (Behrend, 1990; Forbes and Farrar, 1993; Kersten and Smith, 2002; Imai et al., 2005; Hirsh-Pasek and Golinkoff, 2006; Yoshida, in press). The main finding from the study of children's interpretations of novel adjectives using this kind of task is that it is very hard for them; without strong linguistic and contextual support - and sometimes not even then - they do not interpret novel words as 
labeling properties. The present study was motivated in part by the hypothesis that young children's strong tendencies to map novel words to object categories actively interferes with the mapping of a novel adjective to a property of the object. In this view, adjective learning is like an executive control task in that it requires inhibiting a pre-potent tendency. Although many researchers who study of early lexical development have written about children's bias for interpreting novel words as nouns (see, e.g., Mintz and Gleitman, 2002), no research has linked this difficulty, nor its resolution, to the general cognitive mechanism of executive control. We suspect that adjective learning is not the only aspect of language learning to require such processes; indeed, children's errors in verb learning (Behrend, 1990; Golinkoff et al., 2002; Kersten and Smith, 2002), in understanding causal constructions (Smiley and Huttenlocher, 1995; Casasola, 2005), and in understanding passives (Brooks and Tomasello, 1999) may show similar dependencies between executive control and language processing and learning.

This proposal that executive control plays a role in early word learning may be related to more general and widely accepted ideas about lexical access. By the contemporary view of lexical processing, a spoken (or seen) word simultaneously activates many potential lexical and semantic representations and these compete with more strongly activated representations inhibiting weaker ones (Tanenhaus et al., 1995; Rodd et al., 2002; Gaskell and Dumay, 2003). Recent studies of children's on-line word comprehension indicate that these competitive processes also play a role in children's lexical processing and moreover change with development (Snedeker and Trueswell, 2004; Fernald et al., 2008; Snedeker and Yuan, 2008; Vouloumanos and Werker, 2009; Mayor and Plunkett, 2010; Yu and Smith, 2010). For example, Fernald et al. (2008) found that 24-month-olds more rapidly shifted attention to the named referent given a heard word than did 18-month-olds. Fernald et al. (2010) found that 36-month-olds rapidly resolved the word-meaning competition upon hearing the adjective in a red car given a scene with a red car and a blue car, whereas 30-montholds waited until they heard the noun. This could reflect a more rapid resolution of lexical competition in older than younger word learners (Gershkoff-Stowe, 2002). A growing number of child language researchers have suggested that competitive processes such as these may also play a crucial role in word learning itself (Hollich et al., 2000; Halberda, 2009; Horst et al., 2010; Smith et al., 2010; Yoshida and Hanania, in press) through on-line processes that bind known words to known referents thereby leaving unknown words and referents highlighted for possible pairing. Accounts of lexical competition presume that the resolution of that competition is resolved by the strength of the activated representations. Our suggestion is that executive control processes may also play a role. This idea has precedent in several theories of adult cognitive processing outside of the domain of lexical access (Desimone, 1998; Kastner et al., 2001; O'Reilly, 2001; Beck and Kastner, 2005). The point is that the processes that are believed to underlie lexical processing in general are compatible with mechanisms through which executive control processes might directly influence lexical competitions. The finding of a correlation between children's attentional control in a non-linguistic task and in a word-learning task supports this idea.

\section{WORD LEARNING AND ATTENTIONAL CONTROL IN BILINGUAL CHILDREN}

The present results also show that bilingual children are advanced relative to monolingual children in a non-linguistic and a linguistic task, each of which (by hypothesis) requires attentional control. What is the developmental process that links the bilingual advantage in these two tasks? One possibility is that learning and using two languages creates a general advance in executive control and this influences performance a variety of cognitive tasks, including mapping a novel adjective to a property. Another possibility is that the connection is deeper and more intertwined: that learning two languages creates competition among the same kinds of lexical processes that also involved in using and learning just one language and thereby, not only yields better executive control more generally, but also yields advantages in word learning itself. We suspect that the advanced attentional control observed in bilingual children may be the product of several different components of language learning and use, including learning two lexicons, managing the contexts of language use, and managing lexical access. Recent research indicates that the bilingual advantage in advantage in attentional control begins very early. In particular, Kovács and Mehler (2009) reported stronger executive control in a visual task in 7 months olds who had heard two languages from birth. These infants did not yet produce any words in either language and thus receptive language processes, and perhaps the competitions inherent is hearing and representing heard words from multiple languages, may be sufficient to induce better attentional control. If this is so, then, advantages in attentional control in bilingual children may originate in the lexical competitions inherent to mapping words to potential meanings and may therefore also have a direct effect on the lexical competitions that matter to early word learning in each language. The idea of a possibly mechanistic connection between lexical competition and attentional control is also supported by recent findings showing that lexical access and attentional control involve overlapping neural circuits, both in bilinguals (Abutalebi et al., 2008; Bialystok et al., 2008) and in monolinguals (Sommers and Danielson, 1999; Anderson, 2003; Prabhakaran et al., 2006).

One implication of this line of reasoning is that basic processes of word learning - within a single language - may be different for bilinguals and for monolinguals. There is prior evidence suggesting that children learning two languages employ at least somewhat different word-learning processes or strategies than children learning just one language. For example, evidence from artificial noun learning tasks suggests that bilingual and monolingual children (Kan and Kohnert, 2008) differ in the degree and contexts in which they adhere to the hypothesized mutual-exclusivity assumption of one label per object (Merriman and Kutlesic, 1993; Davidson et al., 1997; Davidson and Tell, 2005; Cook et al., 2006; Byers-Heinlein and Werker, 2009). This is interesting given that several researchers have suggested hat mutual-exclusivity may emerge from competitive and inhibitory processes (see Halberda, 2009; Smith et al., 2010). The standard task that is used to test mutual-exclusivity presents children with a well-known object and a well-known name (e.g., a cup) and a novel unnamed object and then asks children to select an object, using a novel label (e.g., "Find the 
dax"). Young monolingual children consistently map the novel label to the novel object (Markman and Wachtel, 1988; Markman, 1989; Merriman and Bowman, 1989). Recent studies using variants of this task and very young children (17-month-olds) indicate that this bias is weaker and/or emerges later in bilingual children (Byers-Heinlein and Werker, 2009; Houston-Price et al., 2010). Other evidence suggests that by 30 months, bilingual children show mutual-exclusivity effects as strong as those of monolingual children (Frank and Poulin-Dubois, 2002) although this may depend on the similarities and differences in the structural features of the two languages (see Kan and Kohnert, 2008). If mutual-exclusivity arises in monolingual children as a form of competition resolution (Regier, 2003, 2005; Halberda, 2009), then these results along with the present ones may mean that the development of lexical competition is fundamentally different for bilingual children both within and across the languages being learned.

One informative domain for examining the role of lexical competition in bilingual word-learning concerns translational equivalents. It has been suggested that early bilingual vocabularies consist of words that are unique to each language with little overlap between the languages - as if bilingual children at first avoid dual labels for the same concept (Barrett, 1978; Volterra and Taeschner, 1978; Redlinger and Park, 1980; Vihman, 1985; Clark, 1987, 1993, but see Pearson and Fernández, 1994; Pearson et al., 1995; Deuchar and Quay, 2000; Nicoladis and Secco, 2000; Marchman and Martinez-Sussmann, 2002; Oller and Pearson, 2002; Bedore et al., 2005, for developmental trajectories). An examination of the strength of this early limitation on translational equivalents and its relation to executive control measures in word-learning and not word-learning tasks could be revealing. Perhaps, for example, young bilinguals limit translational

\section{REFERENCES}

Abutalebi, J., Annoni, J. M., Zimine, I., Pegna, A. J., Seghier, M. L., Hannelore, L. J., and Khateb, A. (2008). Language control and lexical competition in bilinguals: an eventrelated fMRI study. Cereb. Cortex 18, 1496-1505.

Anderson, M. C. (2003). Rethinking interference theory: executive control and the mechanisms of forgetting. J. Mem. Lang. 49, 415-445.

$\mathrm{Au}, \mathrm{T} . \mathrm{K}$., and Glusman, M. (1990). The principle of mutual exclusivity in word learning: to honor or not to honor? Child Dev. 61, 1474-1490.

Au, T. K., and Laframboise, D. E. (1990). Acquiring color names via linguistic contrast: the influence of contrasting terms. Child Dev. 61, 1808-1823.

$\mathrm{Au}, \mathrm{T}$. K., and Markman, E. M. (1987). Acquiring word meaning via linguistic contrast. Cogn. Dev. 2, 217-236.

Barrett, M. D. (1978). Lexical development and overextension in child language. J. Child Lang. 5, 205-219.

equivalents because they cannot yet well control through executive processes lexical competitions between the two languages. For bilinguals, lexical competition across languages may also depend critically on the set of words known in the two languages, their similarity and the crowdedness of lexical neighborhoods. This may be the reason that children's lexical learning strategies may differ when children are tested in one language versus the other (Wilkinson and Mazzitelli, 2003). There are also, of course, a variety of other potentially relevant factors with respect to lexical competition, lexical learning, and executive control in bilingual children that also deserve consideration, including how much children use the dominant language (Conboy and Mills, 2006; Ramon-Casas et al., 2009), cultural experiences that are related to home language (Hakuta and D'Andrea, 1992; Golberg et al., 2008), and the structural relationship between the two languages (Cummins, 1979; Müller, 1998; Müller and Hulk, 2001; Bialystok et al., 2005). In brief, the study of attentional control and lexical competition in children with different language learning histories of various kinds may provide a rich window not just into how learning multiple languages leads to increased attentional control but also into the role of attention and attentional control in lexical learning generally.

\section{ACKNOWLEDGMENTS}

This research was supported in part by Indiana University, University of Houston, a National Institutes of Health grant (R01 HD058620), the Foundation for Child Development, and University of Houston's Grants to Enhance and Advance Research (GEAR) program. We thank the children and parents, who participated in this study. Thanks are also due to Linda B. Smith at Indiana University for her valuable support for research and manuscript development.

access in younger and older bilinguals. J. Exp. Psychol. Learn. Mem. Cogn. 34, 859-873.

Bialystok, E., and Martin, M. M. (2004). Attention and inhibition in bilingual children: evidence from the dimensional change card sort task. Dev. Sci. 7, 325-339.

Bialystok, E., McBride-Chang, C., and Luk, G. (2005). Bilingualism, language proficiency, and learning to read in two writing systems. J. Educ. Psychol. 97, 580-590.

Bialystok, E., and Shapero, D. (2005). Ambiguous benefits: the effect of bilingualism on reversing ambiguous figures. Dev. Sci. 8, 595-604.

Bialystok, E., and Viswanathan, M. (2009). Components of executive control with advantages for bilingual children in two cultures. Cognition 112, 494-500.

Blaga, O. M., and Colombo, J. (2006). Visual processing and infant ocular latencies in the overlap paradigm. Dev. Psychol. 42, 1069-1076.

Brady, T. F., and Chun, M. M. (2007). Spatial constraints on learning in visual search: modeling contextual cuing. J. Exp. Psychol. 33, 798-815.

Brooks, P., and Tomasello, M. (1999). Young children learn to produce passives with nonce verbs. Dev. Psychol. 35, 29-44.

Byers-Heinlein, K., and Werker, J. F. (2009), Monolingual, bilingual, trilingual: infants' language experience influences the development of a word-learning heuristic. Dev. Sci. 12, 815-823.

Carey, S. (1978). "The child as word learner," in Linguistic Theory and Psychological Reality, eds M. Halle, J. Bresnan, and G. Miller (Cambridge, MA: MIT Press), 264-293.

Carey, S., and Bartlett, E. (1978). Acquiring a single new word. Proc. Stanford Child Lang. Conf. 15, 17-29.

Carlson, S. M., and Meltzoff, A. N. (2008). Bilingual experience and executive functioning in young children. Dev. Sci. 11, 282-298.

Casasola, M. (2005). When less is more: how infants learn to form an abstract categorical representation of support. Child Dev. 76, 279-290. 
Chun, M. M., and Jiang, Y. (1998). Contextual cueing: implicit learning and memory of visual context guides spatial attention. Cogn. Psychol. 36, 28-71.

Clark, E. V. (1987). "The principle of contrast: a constraint on language acquisition," in Mechanisms of Language Acquisition, ed. B. Mac Whinney (Hillsdale, NJ: Erlbaum), 1-33.

Clark, E. V. (1993). The Lexicon in Acquisition. Cambridge: Cambridge University Press.

Clark, E. V. (1997). Conceptual perspective and lexical choice in acquisition. Cognition 64, 1-37.

Conboy, B. T., and Mills, D. L. (2006). Two languages, one developing brain: event-related potentials to words in bilingual toddlers. Dev. Sci. 9, F1-F12.

Conboy, B. T., Sommerville, J. A., and Kuhl, P. K. (2008). Cognitive control factors in speech perception at 11 months. Dev. Psychol. 44, 1505-1512.

Conboy, B. T., and Thal, D. J. (2006). Ties between the lexicon and grammar: cross-sectional and longitudinal studies of bilingual toddlers. Child Dev. 77, 712-735.

Cook, V., Bassetti, B., Kasai, C., Sasaki, M., and Takahashi, J. A. (2006). Do bilinguals have different concepts? The case of shape and material in Japanese L2 users of English. Int. J. Biling. 10, 137-152.

Costa, A., Hernández, M., and Sebastián-Gallés, N. (2008). Bilingualism aids conflict resolution: evidence from the ANT task. Cognition 106, 59-86.

Cummins, J. (1979). Linguistic interdependence and the educational development of bilingual children. Rev. Educ. Res. 49, 222-251.

Davenport, J. L., and Potter, M. C. (2004). Scene consistency in object and background perception. Psychol. Sci. 15, 559-564.

Davidson, D., Jergovic, D., Imami, Z., and Theodos, V. (1997). Monolingual and bilingual children's use of the mutual exclusivity constraint. J. Child Lang. 24, 3-24.

Davidson, D., and Tell, D. (2005). Monolingual and bilingual children's use of mutual exclusivity in the naming of whole objects. J. Exp. Child Psychol. 92, 25-45.

Desimone, R. (1998). Visual attention mediated by biased competition in extrastriate visual cortex. Philos. Trans. R. Soc. Lond. B Biol. Sci. 353, 1245-1255.

Desimone, R., and Duncan, J. (1995). Neural mechanisms of selective visual attention. Annu. Rev. Neurosci. 18, 193-222.
Deuchar, M., and Quay, S. (2000). Bilingual Acquisition: Theoretical Implications of a Case Study. Oxford: Oxford University Press.

Diamond, A., Werker, J. F., and LaLonde, C. (1994). "Toward understanding commonalities in the development of object search, detour navigation, categorization, and speech perception," in Human Behavior and the Developing Brain, eds G. Dawson and K. W. Fischer (New York: Guilford Press), 380-426.

Dixon, W. E. Jr., and Smith, P. H. (2000). Links between early temperament and language acquisition. Merrill Palmer Q. 46, 417-440.

Dixon, W. E. Jr., and Smith, P. H. (2008). Attentional focus moderates habituation-language relationships: slow habituation may be a good thing. Infant Child Dev. 17, 95-108

Dromi, E. (1987). Early Lexical Development. Cambridge: Cambridge University Press.

Duncan, J. (1984). Selective attention and the organization of visual information. J. Exp. Psychol. Gen. 113, 501-517.

Fan, J., McCandliss, B. D., Sommer, T., Raz, A., and Posner, M. I. (2002). Testing the efficiency and independence of attentional networks. J. Cogn. Neurosci. 14, 340-347.

Fenson, L., Dale, P. S., Reznick, J. S., Thal, D., Bates, E., Hartung, J. P., Pethick, S., and Reilly, J. S. (1993). The MacArthur Communicative Development Inventories: User's Guide and Technical Manual. San Diego, CA: Singular Publishing Group.

Fernald, A., Thorpe, K., and Marchman, V. A. (2010). Blue car, red car: developing efficiency in online interpretation of adjective-noun phrases. Cogn. Psychol. 60, 190-217.

Fernald, A., Zangl, R., Portillo, A. L., and Marchman, V. A. (2008). "Looking while listening: using eye movements to monitor spoken language comprehension by infants and young children," in Language Processing in Children, eds I. Sekerina, E. Fernández, and $\mathrm{H}$. Clahsen (Amsterdam: Benjamins), 97-135.

Forbes, J. N., and Farrar, J. M. (1993). Children's initial assumptions about the meaning of novel motion verbs: biased and conservative? Cogn. Dev. 8, 273-290.

Frank, I., and Poulin-Dubois, D. (2002) Young monolingual and bilingual children's responses to violation of the mutual exclusivity principle. Int. J. Biling. 6, 125-146.

Gaskell, M. G., and Dumay, N. (2003). Lexical competition and the acquisition of novel words. Cognition 89, 105-132.

Gasser, M., and Smith, L. B. (1998) Learning nouns and adjectives: a connectionist account. Lang. Cogn. Process. 13, 269-306.

Gentner, D. (1982). "Why nouns are learned before verbs: linguistic relativity versus natural partitioning," in Language Development, Language, Thought and Culture, Vol. 2, ed. S. A. Kuczaj II (Hillsdale, NJ: Lawrence Erlbaum Associates), 301-334.

Gershkoff-Stowe, L. (2002). Object naming, vocabulary growth, and the development of word retrieval abilities. J. Mem. Lang. 46, 665-687.

Goetz, P. (2003). The effects of bilingualism on theory of mind development. Biling. Lang. Cogn. 6, 1-15.

Golberg, H., Paradis, J., and Crago, M. (2008). Lexical acquisition over time in minority L1 children learning English as a L2. Appl. Psycholinguist. 29, 41-65.

Golinkoff, R. M., Chung, H. L., HirshPasek, K., Liu, J., Bertenthal, B. I., Brand, R., Maguire, M. J., and Hennon, E. (2002). Young children can extend motion verbs to point-light displays. Dev. Psychol. 38 , 604-614.

Grosjean, F. (1998). Studying bilinguals: methodological and conceptual issues. Biling. Lang. Cogn. 1, 131-149.

Grossberg, S. (1982). Processing of expected and unexpected events during conditioning and attention: a psychophysiological theory. Psychol. Rev. 89, 529-572.

Hakuta, K., and D'Andrea, D. (1992) Some properties of bilingual maintenance and loss in Mexican background high-school students. Appl. Linguist. 13, 72-99.

Halberda, J. (2009). "Mutual exclusivity as logical inference: evidence for domain general disjunctive syllogism in 2-3 year olds," in Talk Presented at the Society for Research in Child Development, Denver, CO.

Hirsh-Pasek, K., and Golinkoff, R. M. (2006). Action Meets Word: How Children Learn Verbs. New York: Oxford University Press.

Hollich, G., Hirsh-Pasek, K., Tucker, M. L., and Golinkoff, R. M. (2000). "A change is afoot: emergentist thinking in language acquisition," in Downward Causation, eds P. Anderson, C. Emmeche, N. O. Finnemann, and P. V. Christiansen (Oxford: Aarhus University Press), 143-178.

Horst, J., Scott, E., and Pollard, J. (2010). The role of competition in word learning via referent selection. Dev. Sci. 13, 706-713.
Houston-Price, C., Caloghiris, Z., and Raviglione, E. (2010). Language experience shapes the development of the mutual exclusivity bias. Infancy 15, 125-150.

Imai, M., Haryu, E., and Okada, H. (2005). Mapping novel nouns and verbs onto dynamic action events: are verb meanings easier to learn than noun meanings for Japanese children? Child Dev. 76, 340-355.

Jackson-Maldonado, D., Bates, E., and Thal, D. J. (2003). MacArthur-Bates inventario deldesarrollo de habilidadescomunicativas (MCDI) version corta en Español. Baltimore, MD: Brookes Publishing.

Jackson-Maldonado, D., Thal, D., Marchman, V., Bates, E., and Gutierrez-Clellen, V. (1993). Early lexi- cal development in Spanishspeaking infants and toddlers. J. Child Lang. 20, 523-549.

Kan, P., and Kohnert, K. (2008). Fast mapping by developing bilinguals in L1 and L2. J. Child Lang. 35, 495-514.

Kastner, S., De Weerd, P., Pinsk, M. A., Elizondo, M. I., Desimone, R., and Ungerleider, L. G. (2001). Modulation of sensory suppression: implications for receptive field sizes in the human visual cortex. J. Neurophysiol. 86, 1398-1411.

Kaushanskaya, M., and Martin, M. M. (2009). The bilingual advantage in novel word learning. Psychon. Bull. Rev. 16, 705-710.

Kersten, A. W., and Smith, L. (2002). Attention to novel objects during verb learning. Child Dev. 73 93-109.

Kersten, A.W., Smith, L.B., and Yoshida, H. (2006). "Influences of object knowledge on the acquisition of verbs in English and Japanese," in Action Meets Word: How Children Learn Verbs, eds K. Hirsh-Pasek and R. M. Golinkoff (New York, NY Oxford University Press), 499-524.

Kovács, Á. M., and Mehler, J. (2009). Cognitive gains in 7-month-old bilingual infants. Proc. Natl. Acad. Sci. U.S.A. 106, 6556-6560.

Kruschke, J. K. (2001). Toward a unified model of attention in associative learning. J. Math. Psychol. 45, 812-863.

Kruschke, J. K. (2003). Attention in Learning. Curr. Dir. Psychol. Sci. 12, 171-175.

Kruschke, J. K., Kappenman, E. S., and Hetrick, W. H. (2005). Eye gaze and individual differences consistent with learned attention in associative blocking and highlighting. J. Exp. Psychol. Learn. Mem. Cogn. 31, 830-845. 
Lalonde, C. E., and Werker, J. F. (1995). Cognitive influences on cross- language speech perception in infancy. Infant Behav. Dev. 18, 459-475.

Landau, B., Smith, L. B., and Jones, S. (1988). The importance of shape in early lexical learning. Cogn. Dev. 3 , 299-321.

Mackintosh, N. J. (1975). A theory of attention: variations in the associability of stimuli with reinforcement. Psychol. Rev. 82, 276-298.

Mani, N., and Plunkett, K. (2007). Phonological specificity of vowels and consonants in early lexical representations. J. Mem. Lang. 57, 252-272.

Marchman, V. A., Martinez-Sussman, C., and Dale, P. S. (2004). The language-specific nature of grammatical development: evidence from bilingual language learners. Dev. Sci. 7, 212.

Marchman, V. A., and MartinezSussmann, C. (2002). Concurrent validity of caregiver/parent report measures of language for children who are learning both English and Spanish. J. Speech Lang. Hear. Res. 45, 983-997.

Markman, E. M. (1989). Categorization and Naming in Children: Problems of Induction. Cambridge, MA: MIT Press.

Markman, E. M., and Wachtel, G. F. (1988). Children's use of mutual exclusivity to constrain the meanings of words. Cogn. Psychol. 20, 121-157.

Mayor, J., and Plunkett, K. (2010). A neurocomputational account of taxonomic responding and fast mapping in early word learning. Psychol. Rev. 117, 1-31.

Medin, D. L., and Schaffer, M. M. (1978). Context theory of classification learning. Psychol. Rev. 85, 207-238.

Merriman, W. E., and Bowman, L. L. (1989). The mutual exclusivity bias in children's word learning. Monogr. Soc. Res. Child Dev. 54, 1-129.

Merriman, W. E., and Kutlesic, V. (1993). Bilingual and monolingual children's use of two lexical acquisition heuristics. Appl. Psycholinguist. 14, 229-249.

Mezzacappa, E. (2004). Alerting, orienting, and executive attention: developmental properties and sociodemographic correlates in an epidemiological sample of young, urban children. Child Dev. 75, 1373-1386.

Mintz, T. H. (2005). Linguistic and conceptual influences on adjective acquisition in 24- and 36-montholds. Dev. Psychol. 41, 17-29.
Mintz, T. H., and Gleitman, L. R. (2002). Adjectives really do modify nouns: the incremental and restricted nature of early adjective acquisition. Cognition 84, 267-293.

Müller, N. (1998). Transfer in bilingual first language acquisition. Biling. Lang. Cogn. 1, 151-171.

Müller, N., and Hulk, A. (2001). Crosslinguistic influence in bilingual language acquisition: Italian and French as recipient languages. Biling. Lang. Cogn. 4, 1-21.

Nelson, K. (1973). Structure and Strategy in Learning to Talk. Monographs of the Society for Research in Child Development, Vol. 38. Chicago, IL: University of Chicago Press.

Nicoladis, E., and Secco, G. (2000). The role of a child's productive vocabulary in the language choice of a bilingual family. First Lang. 58, 3-28.

Ogura, T., and Watamaki, T. (1997). Japanese Communicative Developmental Inventories: User's Guide and Technical Manual. San Diego, CA: Singular.

Ogura, T., Yamashita, Y., Murase, T., and Dale, P. (1993). Some preliminary findings from the Japanese early communicative inventory. Paper presented at the 6th International Conference for Child Language, Trieste.

Oller, D. K., and Pearson, B. Z. (2002). "Assessing the effects of bilingualism: a background," in Language and Literacy in Bilingual Children, eds D. K. Oller and R. E. Eilers (Clevedon: Multilingual Matters), 3-21.

O’Reilly, R. C. (2001). Generalization in interactive networks: the benefits of inhibitory competition and Hebbian learning. Neural. Comput. 13, 1199-1242.

Patterson, J. L., and Pearson, B. Z. (2004). "Bilingual lexical development: influences, contexts, and processes," in Bilingual Language Development and Disorders in Spanish-English Speakers, ed. B. A. Goldstein (Baltimore, MD: Paul H. Brookes), 77-104.

Pearson, B. Z., and Fernández, S. C. (1994). Patterns of interaction in the lexical growth in two languages of bilingual infants and toddlers. Lang. Learn. 44, 617-653.

Pearson, B. Z., Fernández, S. C., and Oller, D. K. (1993). Lexical development in bilingual infants and toddlers: comparison to monolingual norms. Lang. Learn. 43, 93-120.

Pearson, B. Z., Fernánez, S., and Oller, D. K. (1995). Cross-language synonyms in the lexicons of bilingual infants: one language or two? J. Child Lang. $22,345-368$.
Pearson, B. Z. Fernández, S. C., Lewedag, V., and Oller, D. K. (1997). The relation of input factors to lexical learning by bilingual infants (ages 10 to 30 months). Appl. Psycholinguist. 18, 41-58.

Posner, M. I. (1980). Orienting of attention. Q. J. Exp. Psychol. 32, 2-25.

Prabhakaran, R., Blumstein, S. E., and Myers, E. B. (2006). An event-related fMRI investigation of phonologicallexical competition. Neuropsychologia 44, 2209-2221.

Preston, A. R., and Gabrieli, J. D. E. (2008). Dissociation between explicit memory and configural memory in the human medial temporal lobe. Cereb. Cortex 18, 2192-2207.

Ramon-Casas, M., Swingley, D. Sebastián-Gallés, N., and Bosch, L. (2009). Vowel categorization during word recognition in bilingual toddlers. Cogn. Psychol. 59, 96-121.

Redlinger, W. E., and Park, T. Z. (1980). Language mixing in young bilinguals. J. Child Lang. 7, 337-352.

Regier, T. (2003). Emergent constraints on word-learning: a computational review. Trends Cogn. Sci. (Regul. Ed.) 7, 263-268.

Regier, T. (2005). The emergence of words: attentional learning in form and meaning. Cogn. Sci. 29, 819-865.

Rescorla, R. A., and Wagner, A. R. (1972). "A theory of Pavlovian conditioning: variations in the effectiveness of reinforcement and nonreinforcement," in Classical Conditioning II Current Research and Theory, eds A. H. Black and W. F. Prokasy (New York, NY: Appleton-CenturyCrofts), 64-99.

Richards, J. E. (2008). "Attention in young infants: a developmental psychophysiological perspective," in Handbook of Developmental Cognitive Neuroscience, 2nd Edn, eds C. A. Nelson and M. Luciana (Cambridge, MA: MIT Press), 479-497.

Rodd, J., Gaskell, G., and MarslenWilson, W. (2002). Making sense of semantic ambiguity: semantic competition in lexical access. J. Mem. Lang. 46, 245-266.

Rueda, M. R., Fan, J., Halparin, J., Gruber, D., Lercari, L. P., McCandliss, B. D., and Posner, M. I. (2004). Development of attention during childhood. Neuropsychologia 42, 1029-1040.

Sandhofer, C. M., and Smith, L. B. (2007). Learning adjectives in the real world: how learning nouns impedes learning adjectives. Lang. Learn. Dev. 3, 233-267.

Smiley, P., and Huttenlocher, J. (1995). "Conceptual development and the child's early words for events, objects, and persons," in Beyond Names for Things: Young Children's Acquisition of Verbs, eds M. Tomasello and W. E. Merriman (Hillsdale, NJ: Lawrence Erlbaum Associates), 21-62.

Smith, L. B., Colunga, E., and Yoshida, H. (2010). Knowledge as process: contextually-cued attention and early word learning. Cogn. Sci. 34, 1287-1314.

Smith, L. B., Jones, S., and Laundau, B. (1992). Count nouns, adjectives, and perceptual properties in children's novel word interpretations. Dev. Psychol. 28, 273-286.

Snedeker, J., and Trueswell, J. (2004). The developing constraints on parsing decisions: the role of lexicalbiases and referential scenes in child and adult sentence processing. Cogn. Psychol. 49, 238-299.

Snedeker, J., and Yuan, S. (2008). Effects of prosodic and lexical constraints on parsing in young children (and adults). J. Mem. Lang. 58, 574-608.

Sommers, M. S., and Danielson, S. M. (1999). Inhibitory processes and spoken word recognition in young and older adults: the interaction of lexical competition and semantic context. Psychol. Aging 14, 458-472.

Tamis-LeMonda, C. S., and Bornstein, M. H. (1989). Habituation and maternal encouragement of attention in infancy as predictors of toddler language, play, and representational competence. Child Dev. 60, 738-751.

Tanenhaus, M., Spivey-Knowlton, M., Eberhard, K., and Sedivy, J. (1995). Integration of visual and linguistic information during spoken language comprehension. Science 268, 1632-1634

Vihman, M. M. (1985). Language differentiation by the bilingual infant J. Child Lang. 12, 297-324.

Volterra, V., and Taeschner, T. (1978). The acquisition and development of language by bilingual children. $J$. Child Lang. 5, 311-326.

Vouloumanos, A., and Werker, J. F. (2009). Infants' learning of novel words in a stochastic environment. Dev. Psychol. 45, 1611-1617.

Waxman, S. (1990). Linguistic biases and the establishment of conceptual hierarchies. Cogn. Dev. 5 , 123-150.

Waxman, S. R., and Klibanoff, R. S. (2000). The role of comparison in the extension of novel adjectives. Dev. Psychol. 36, 571-581. 
Wilkinson, K. M., and Mazzitelli, K. (2003). The effect of 'missing' information on children's retention of fast-mapped labels. J. Child Lang. $30,47-73$.

Yang, S. (2004). Testing Bilingual Children's Cognitive Advantages in Executive Attention. Unpublished master's thesis, Cornell University, Ithaca, NY.

Yang, S., Shih, J., and Lust, B. (2005). Exploring cognitive advantages of childhood bilingualism through new tests of executive attention. Poster Presented at the
Biennial Meeting of the Society for Research in Child Development, Atlanta, GA.

Yoshida, H. (in press). A crosslinguistic study of sound-symbolism in children's verb learning. J. Cogn. Dev.

Yoshida, H., and Hanania, R. (in press). If it's red, it's not vap: how competition among words may benefit early word learning. First Lang.

Yu, C., and Smith, L. B. (2010). What you learn is what you see: using eye movements to study infant cross- situational word learning. Dev. Sci.

$1-16$.

Conflict of Interest Statement: The authors declare that the research was conducted in the absence of any commercial or financial relationships that could be construed as a potential conflict of interest.

Received: 29 January 2011; accepted: 15 August 2011; published online: 14 September 2011.

Citation: Yoshida H, Tran DN, Benitez V and Kuwabara M (2011) Inhibition and adjective learning in bilingual and monolingual children. Front. Psychology 2:210. doi: 10.3389/fpsyg.2011.00210

This article was submitted to Frontiers in Developmental Psychology, a specialty of Frontiers in Psychology.

Copyright $\odot 2011$ Yoshida, Tran, Benitez and Kuwabara. This is an open-access article subject to a non-exclusive license between the authors and Frontiers Media $S A$, which permits use, distribution and reproduction in other forums, provided the original authors and source are credited and other Frontiers conditions are complied with. 


\section{APPENDIX}

Lists of test phrases used for the adjective task, and known and novel adjectives in the three languages used in the study.

\section{ENGLISH}

See this? This is a [novel adjective] [object name]!

Now, can you give me a [object name] that is [novel adjective]?

Known adjectives bumpy, spotted, shiny, holey

Novel adjectives Blickish, dakish, talish, wuggish

\section{VIETNAMESE}

Em thấy cái này không?

You see this here no?

(See this?)

Con [object name] này thiệt là [novel adjective].

This [object name] here is [novel adjective].

This is a [novel adjective] [object name].

Bây giờ emđưa cho chị một con [object name] thiệt là [novel adjective] được không?
Now you give to me one [object name] [novel adjective] can no?

(Now, can you give me a [object name] that is [novel adjective]?)

Known adjectives

u (bumpy), lỗ (holey), đốm (spotted), bóng (shiny)

Novel adjectives

bi-li (blickish), đách-li (dakish), ta-li (talish), qu-gi (waggish)

\section{SPANISH}

Mirá, este [object name] es [novel adjective].

Look, this [object name] is [novel adjective].

Me podes decir ¿Cual [object name] es [novel adjective]?

Can you tell me which [object name] is [novel adjective]?

(Can you give me a [object name] that is [novel adjective]?)

Known adjectives

bumpy, spotted, shiny, holey

Novel adjectives

blíckish (blickish), dákish (dakish), tálish (talish), wúggish (waggish) 